\title{
Photocoagulation of the iris using direct sunlight
}

\author{
JOHN M. L. OTITI \\ Department of Ophthalmology, Mulago Hospital, Uganda
}

The purpose of this paper is to draw attention to the possibility of photocoagulation of the्e iris with simple and inexpensive equipment if more sophisticated apparatus is not availableir

In the Department of Ophthalmology at Mulago Hospital, Kampala, the teachin hospital of Makerere University College Medical School, we have used the principle of the original Meyer-Schwickerath light-coagulator (Meyer-Schwickerath, I950, 1960). This method depends on the availability of uninterrupted bright sunlight. Other requirements are a strong spherical lens of $+\mathrm{I} 5$ to +20 dioptres, about $38 \mathrm{~mm}$. in diameter, norma saline, and a lid speculum. The operation is carried out under retrobulbar anaesthesia

\section{Technique}

The patient is laid on a couch facing the sun and retrobulbar anaesthesia is induced. Paralysis the orbicularis oculis muscle is optional. A lid speculum is applied. Before bringing the sphericat lens in front of the eye to focus the sun rays onto the iris, it is advisable to try it on a piece of paper to test the focal length and to see whether the sunlight is strong enough. When the right degree $\frac{\text { f }}{3}$ heat is produced the sun rays will burn a hole in the paper.

During the operation, an assistant continuously instills drops of normal saline at room temperature onto the cornea to prevent drying and lessen the risk of damage. If the cornea is not continuousl moistened a haze develops, but this fortunately clears up as soon as the heat is removed. Th? procedure is carried out for only a few seconds at a time, and is interrupted by rest intervals of abou 30 to 60 seconds during which the speculum is removed and the lids drawn over the corneal surfaci several times. Where there are no complications, the desired effect is achieved immediately and is permanent. We have found that applications of 2 to 4 seconds' duration are adequate, and we have never seen a permanent corneal opacity resulting from this procedure. As a precautionary measuro however, we have always avoided focusing the beam of light through the centre of the cornea. It not even necessary to have the patient in an open space outdoors as we have found a steady beam sunlight through an open window just as effective.

Post-operatively the patients are kept in hospital and I per cent. atropine drops and topical ant biotic eye ointment are used with double-padding for 2 to 3 days. They are then discharged on the same treatment for a few more days.

\section{Results}

Eleven patients, of whom ten were aphakic and one phakic, have undergone this treatmer⿳⺈⿴囗十灬 during the last 8 months. In seven of them the operation was successful and there wa范 marked improvement in visual acuity. 


\section{Case reports}

APHAKIC

A typical example was a patient who was blind in one eye, the other being aphakic with a very small and drawn-up pupil. The lower border of the pupil in the aphakic eye was about $2 \mathrm{~mm}$. from the upper limbus and the visual acuity was counting fingers at $0 \cdot 5 \mathrm{~m}$. After photocoagulation of the iris by the method described, the lower border of the pupil was brought down to about $6 \mathrm{~mm}$. from the upper limbus. The visual acuity improved to 6/6o uncorrected, and with aphakic spectacle correction it was $6 / 9$.

PHAKIC

A man aged 32 had sustained blunt injuries to both eyes 3 years previously and cataracts had subsequently developed. The lens had been extracted from the right eye which had a drawn-up pupil and had been successfully treated by iris photocoagulation.

The pupil in the left eye was completely occluded by posterior synechize onto the anterior pole of the lens. One could, however, observe brisk action of the sphincter, on shining a strong light into the eye. The visual acuity in this eye was only perception of light with good light projection in all directions. After photocoagulation of the left iris as described above, the adhesion in the left eye broke away from the centre and a dense cataract was seen at the anterior pole. A good-sized pupil of about $4 \mathrm{~mm}$. in diameter was reformed and no further lens opacity developed. The visual acuity improved from perception of light to counting fingers at $2 \mathrm{~m}$., but vitreous opacities were also present.

In the four cases which were not so successful, there were firm posterior synechiae either to lens remnants or to the anterior surface of the vitreous. Of the seven successful cases, five returned to the follow-up clinic. The pupillary size remained about the same as immediately after the operation. Slit-lamp examination showed no corneal damage.

\section{Comment}

Although it appears that the iris absorbs most if not all of the heat so that little or no damage is done to the lens, the method should not be used in cases with a normal lens. Meyer-Schwickerath (1960) noted that iris coagulation produced small non-progressive subcapsular opacities in a normal clear lens; this is even more likely when direct sunlight is used.

\section{Summary}

Photocoagulation of the iris in cases of distorted and displaced pupil has been carried out by means of sunlight directed through a strong spherical lens. The procedure works successfully and quickly provided that there are no strong adhesions. Continuous instillation of normal saline drops is essential to reduce the risk of corneal damage. This is a simple practical method if elaborate photocoagulators are not available.

I am grateful to our former professor, Prof. Martin Davanger, M.D., for his encouragement in writing this paper.

\section{References}

MeYer-SchWickerath, G. (1950) Ber. 55. dtsch. ophthal. Ges., Heidelberg, I949, p. 256

- (1960) “Light Coagulation", trans. S. M. Drance. Mosby, St. Louis 